\title{
GENDER INEQUALITY IN THE WORKPLACE (働き方の男女不平等 理論と害証分析) BY KAZUO YAMAGUCHI (TOKYO, NIKKEI PUBLISHING INC, 2017)
}

IIDA AKI

Although five years have passed since the Abe administration announced the intention of strengthening women's participation in the labour market as part of a national growth strategy, there has been no increase in Japan. Rather, the ranking of Japan in the Global Gender Gap reports has declined year by year: 101st out of 145 in 2015, 111th out of 144 in 2016, and 114th out of 144 in 2017 (World Economic Forum, 2015; 2016; 2017). The Act on Promotion of Women's Participation and Advancement in the Workplace came into force in 2016 April to strengthen the Abe administration's growth strategy in relation to the female workforce. According to this law, companies which have over 301 employees, as well as central and local governments, are required to draw up and publish a "Plan" for promoting women employees into managerial positions and providing a supporting environment, with targeted numbers: the aim is to have $30 \%$ of female managers by 2020 (Gender Equality Bureau Cabinet Office, 2016: 28). However, there is a big gap between the aims announced by the government and the actual situation in Japan - although only two years have passed since this law came into force, hence its effects cannot yet be seen.

According to the Japanese lifetime employment system, it is important how long one has been employed at a company: the term Kinzoku stands for the number of years one remains at one company as an employee: other specific terms include Ippan-syoku and Sogo-syoku; Ippan meaning "General" in English, and Sogo meaning "Integration/Comprehensive" (Syoku generally means "job"). The notion of Ippan-syoku was born after the Equal Employment Opportunity Law was enacted in 1985. Due to this law, companies could not discriminate in terms of the wages paid to male employees who were expected to become managers and those paid to female employees who were expected

1 Iida Aki is a Ph.D. student at the Doctoral School of Sociology, Corvinus University of Budapest; e-mail: aki.iida@uni-corvinus.hu 
to take up supporting jobs. Sogo-syoku and Ippan-syoku were thus conceived to make it possible to maintain the system of wage differences as they existed before the law: those who are expected to become managers, typically men, are called Sogo-syoku (77.8\% of those newly hired as Sogo-syoku in 2014 were men). At the beginning, Ippan-syoku was only applied to women. Although this women-only classification is now illegal, the legacy remains: more than $80 \%$ of Ippan-syoku newly hired in 2014 were female. A careful investigation of likely future changes in Japanese companies regarding gender inequality is thus a matter of great significance, and the book which is here reviewed will be valuable as early research. The text is particularly recommended for those who research gender imbalances and inequality in the labour market.

In the book, the author Kazuo Yamaguchi (the Hanna Holborn Gray Professor of Sociology at the University of Chicago) scientifically and empirically analyzes gender inequality in Japanese workplaces over eight chapters, mainly using statistical data. The purpose is to clearly quantify what kinds of inequality exist. Regarding the data used for the analysis in the book, a Japanese company survey in 2009 conducted by the independent administrative institution under the Ministry of Economy, Trade and Industry (a policy think-tank established in 2001, of which Yamaguchi is a visiting researcher) is used throughout.

First, in analyzing the gender gap among managers, Yamaguchi seeks empirical evidence that a conservative corporate culture is the source of gender inequalities and discrimination against women in Japan. According to the official statistics, the proportion of female managers in 2011 was $7.4 \%$ in companies with 500-1000 employees, and 5.8\% in companies with over 1000 employees, while $45 \%$ of companies which had over 30 employees did not have any female managers. These numbers are extremely low compared to Western standards (Ministry of Health, Labor and Welfare, 2012).

Companies claim that this problem is due to the lack of Kinzoku years and experience of women, etc. However, Yamaguchi points out that companies do not mention the existence of discrimination against women that is in-built into their employment systems, including indirect discrimination, as a cause. Yamaguchi clarifies the existence of this discrimination through analyses. Specifically, the database previously mentioned contains 6480 males and 3023 females aged 2359 who are engaged in 1677 companies. Yamaguchi measures the percentage of managers, including the position of subsection chief, by gender, along with the percentage of managers by gender using the five-year classifications of Kinzoku years, which start from the year of entry into the current workplace. Results indicate that in the first 25 years after employees join their company, the proportion of female managers, including subsection chiefs, is $10 \%$ or less, while in the sample of those who entered companies between 1980 to 1984 the 
proportion is $14 \%$ (i.e. 26 to 30 years after the women joined the companies). However, men who only entered companies after 2005 reach proportions of more than $14 \%$ of all managers, including subsection chiefs. This means that such men spent less than five years working before reaching such positions, while those who entered companies between 1995 to 1999 (i.e. those who spent 11 - 15 years at the company) account for $20 \%$ of managers. It is thus clear that men achieve within five years of starting work what women need to spend over 26-30 years to achieve (and that men achieve in 11-15 years what women do throughout their entire careers). Namely, companies' excuses about women's short Kinzoku years, etc. are not valid. Accordingly, Yamaguchi has drawn up two hypotheses, in addition to assessing variables such as employees' academic background and age. The results of previous research by the authors focused on the responses given by employees in a large firm that showed that long working hours do not affect the rate of promotion of men, but do limit the opportunities of women. Based on this fact, Yamaguchi's hypothesis is that the difference in working hours affects the rate of promotion, that working hours are different for men and women, and that the relationship between the rate of promotion and long working hours was stronger for women than for men. Furthermore, based on the division of labour by gender that is still persistent in Japanese society, if age and other individual-level attributes are kept constant, those male employees who have children obtain higher managerial positions than those who have wives without children, while in the case of women the situation is reversed. Yamaguchi also supposes that differences in inter-company policies such as whether the company seeks to use the abilities of employees, regardless of sex, and whether companies seek to promote a decent work-life balance also affect the promotion of men and women.

Yamaguchi decomposes the gender gap between men and women into an "explainable" and an "unexplainable" part and analyses it further. The hypotheses are supported, except in the case that companies try to exploit the abilities of employees, regardless of sex (this affects the chance of promotion). However, even if women were equivalent to men in terms of human capitalrelated characteristics (age, educational background, employment experience, etc.) most of the gap between men and women could still not be explained: it was found that only $21 \%$ of gender inequality in the proportion of managers can be explained by referring to characteristic differences in human capital, and only $30 \%$ of gender inequality in the proportion of managers including position of section chief. Among the remaining gaps, working hours can be potentially be explained by wider cultural differences between men and women, which are more difficult to resolve. For example, there is still a significant gap in the amount of unpaid work in families between husbands and wives $(90 \%$ of the 
housework burden falls on the wife in the case of a regular employee couple). Men's participation at home in Japan is the least of any G7 country and much lower than OECD average (The Ministry of Health, Labour, and Welfare, 2008; OECD, 2014). In addition, Yamaguchi points out that even if the known gender differences between working hours and human capital are combined, this only explains about $40 \%$ of the difference in the gender gap in the proportion of managers, including subsection chiefs. Therefore, about $60 \%$ of the gender inequality found in companies in Japan cannot be explained or justified. In attempting to explain this remarkable difference, it is unreasonable to exclude the impact of Sogo-syoku and Ippan-syoku, which are unique elements of the employment system in Japan.

In the second part of the book, Yamaguchi focuses on the income gap between men and women and is able to explain about $80 \%$ of the difference. Results are in line with the previously presented tendencies. More than three-quarters of the difference is explained by five variables, including educational background, age, Kinzoku years, occupation and job-ranking. The fact that $80 \%$ of the income gap between men and women can be explained represents specific help for improving the situation and should be considered a great achievement. Moreover, the weight of the two variables occupation and job-ranking are significant, thus it can be said that the low rate of promotion of women (as previously shown) is the main factor in the income gap between men and women. It is important to know that if you are a woman and are occupied as a clerk (similar to Ippan-syoku), this is a career deadend and promotion cannot be expected regardless of Kinzoku years. However, Yamaguchi points out that the income gap between men and women is greater in terms of human-capital-related factors such as academic background, age, and Kinzoku years (instead of occupation and job-ranking) after employees reach managerial positions. If women have the same human capital as men, there is almost no income gap in the managerial positions, thus if women can attain promotion they have a chance of being equally treated.

Yamaguchi also finds that the existence of policies about the (gender-based) equality of opportunities at the company level play an important role in reducing the income gap; when such policies exist, they are found to increase women's income. However, companies in which only a work-life balance policy exists actually have a larger income gap, suggesting that specific instruments that promote gender equality of opportunities are required. This may be why companies that do not have a policy that supports the gender equality of opportunities employ a lot of female employees with low wages through their work-life balance policies; they promote a so-called "Mommy track." As worklife-balance policies are accompanied by such risks, diversity management is indispensable for narrowing the income gap between men and women. 
Additionally, Yamaguchi finds that GDP per hour and the degree of gender equality (using a Gender Empowerment Measure) are positively correlated in OECD countries, and there is also a strong correlation between gender equality and hourly labour productivity. The analysis of Japanese companies suggests that if the proportion of female managers increases while the proportion of women's regular full-time employees remains constant, the productivity and competitiveness of companies will increase. However, if the number of regular full-time female employees increases while the proportion of female managers remains constant, productivity and the competitiveness of companies will decrease. Furthermore, when there are many male employees with a university degree, the productivity and competitiveness of companies is increased, while female university degree holders do not have this influence; however, as far as companies with a policy that promotes the gender equality of opportunities are concerned, an increase in university graduates increases productivity and competitiveness. From this fact it is suggested that Japanese companies do not exploit the abilities of women university graduates. Based on these findings, Yamaguchi supposes that discrimination against women creates different incentives for male and female self-investment. As a consequence, indirect discrimination against women lessens the incentive for men and women to self-invest, although in jobs where it is difficult to get a job even after selfinvestment, the gender gap in relation to positions becomes larger. Moreover, in the opposite case it was found that the degree of achievement in terms of the position of females may exceed that of males in some cases. This finding is consistent with the idea that the existence of a policy that promotes the gender equality of opportunities affects women's success.

Throughout the book, Yamaguchi explains Japan's unique employment system and clarifies its differences with the systems of the West. He also explains what the defects and weaknesses of the formulae and data he uses are in detail before and each analysis. The theme of each chapter is understandable and clear, and logically summarizes the purpose, hypotheses, theoretical framework and methods therein. By undertaking all analyses using concrete data, the author succeeds in eliminating any grounds for criticism on the basis of subjectivity. However, the addition of some qualitative research (such as interviews and case studies about the psychological status of women in workplaces) may have more strongly verified the claim that company policy is able to promote the activity of women and affect women's motivation to pursue Kinzoku, thereby further supporting the findings of the book. If the proposed studies can be conducted, Yamaguchi's claim that the biggest corrective of gender inequality in the labour market would not be to decrease the income gap between men and women but to narrow the labour productivity gap between men and women could be strengthened. 
